Annals of Pure and Applied Mathematics

Vol. 12, No. 2, 2016, 153-159

ISSN: 2279-087X (P), 2279-0888(online)

Published on 11 November 2016

www.researchmathsci.org

DOI: 10.22457/apam.v12n2a6

Annals of

Pure and Applied

Mathematics

\title{
Fuzzy PMS Ideals in PMS Algebras
}

\section{P.M.Sithar Selvam ${ }^{1}$ and K.T.Nagalakshmi ${ }^{2}$}

${ }^{1}$ Department of Mathematics, R.V.S. School of Engineering and Technology

Dindigul- 624 001, Tamilnadu, India

E-mail : sitharselvam@gmail.com

${ }^{2}$ Department of Mathematics, K.L.N.College of Information and Technology

Pottapalayam- 630611, Sivagangai District, Tamilnadu, India

E-mail: gloryratna@gmail.com

Received 25 October 2016; accepted 10 November 2016

Abstract. In this paper, a new notion, namely fuzzification of PMS-algebra, a generalization of BCK/BCI/TM/KUS/PS-algebras is initiated along with fuzzified PMSideal and discussed some of its properties in detail.

Keywords: PMS-algebra, fuzzy PMS-subalgebra, fuzzy PMS-ideal, homomorphism, Cartesian product.

AMS Mathematics Subject Classification (2010): 20N25, 03E72, 03F055, 06F35

\section{Introduction}

In 1965, the concept of fuzzy set was introduced by Zadeh [15]. In 1978, Iseki and Tanaka [1] introduced the concept of BCK-algebras and in 1980 Iseki [2] introduced the concept of BCI-algebras. In 2015, Sithar Selvam and Nagalakshmi [4,5] introduced a new algebraic structure, named as PMS algebras, as a generalization of $\mathrm{BCK} / \mathrm{BCI} / \mathrm{TM} / \mathrm{KUS} / \mathrm{PS}$-algebras. In this paper we fuzzified PMS-algebras and studied its properties in detail along with fuzzy PMS-ideal, homomorphism and Cartesian products.

\section{Preliminaries}

In this section, we present the fundamental definitions that will be used in the development of this paper.

Definition 2.1. $[1,14]$ A BCK- algebra is an algebra $(X, *, 0)$ of type $(2,0)$ satisfying the following conditions:
i) $(\mathrm{x} * \mathrm{y}) *(\mathrm{x} * \mathrm{z}) \leq(\mathrm{z} * \mathrm{y})$
ii) $\mathrm{x} *(\mathrm{x} * \mathrm{y}) \leq \mathrm{y}$
iii) $\mathrm{x} \leq \mathrm{x}$
iv) $\mathrm{x} \leq \mathrm{y}$ and $\mathrm{y} \leq \mathrm{x} \Rightarrow \mathrm{x}=\mathrm{y}$
v) $0 \leq \mathrm{x} \Rightarrow \mathrm{x}=0$, where $\mathrm{x} \leq \mathrm{y}$ is defined by $\mathrm{x} * \mathrm{y}=0$, for all $\mathrm{x}, \mathrm{y}, \mathrm{z} \in \mathrm{X}$. 


\section{P.M.Sithar Selvam and K.T.Nagalakshmi}

Definition 2.2. [4,5] A nonempty set $X$ with a constant 0 and a binary operation ' *' is called PMS - algebra if it satisfies the following axioms.

1. $0 * \mathrm{x}=\mathrm{x}$

2. $(\mathrm{y} * \mathrm{x}) *(\mathrm{z} * \mathrm{x})=\mathrm{z} * \mathrm{y}, \forall \mathrm{x}, \mathrm{y}, \mathrm{z} \in \mathrm{X}$.

In $X$, we define a binary relation $\leq$ by : $\mathrm{x} \leq \mathrm{y}$ if and only if $\mathrm{x} * \mathrm{y}=0$.

Definition 2.3. $[4,5]$ Let $X$ be a PMS - algebra and I be a subset of X, then I is called a PMS - ideal of $X$ if it satisfies the following conditions:

1. $0 \in \mathrm{I}$

2. $\mathrm{z} * \mathrm{y} \in \mathrm{I}$ and $\mathrm{z} * \mathrm{x} \in \mathrm{I} \Rightarrow \mathrm{y} * \mathrm{x} \in \mathrm{I}$ for all $\mathrm{x}, \mathrm{y}, \mathrm{z} \in \mathrm{X}$.

Example 2.4. Let $X=\{0,1,2\}$ be the set with the following table.

Then $(\mathrm{X}, *, 0)$ is a PMS - algebra.

\begin{tabular}{|r|r|r|r|}
\hline$*$ & 0 & 1 & 2 \\
\hline 0 & 0 & 1 & 2 \\
\hline 1 & 2 & 0 & 1 \\
\hline 2 & 1 & 2 & 0 \\
\hline
\end{tabular}

Example 2.5. Let $X=\{0, a, b, c\}$ be the set with the following table.

\begin{tabular}{|l|l|l|l|l|}
\hline$*$ & 0 & $\mathrm{a}$ & $\mathrm{b}$ & $\mathrm{c}$ \\
\hline 0 & 0 & $\mathrm{a}$ & $\mathrm{b}$ & $\mathrm{c}$ \\
\hline $\mathrm{a}$ & $\mathrm{b}$ & 0 & $\mathrm{a}$ & $\mathrm{b}$ \\
\hline $\mathrm{b}$ & $\mathrm{a}$ & $\mathrm{b}$ & 0 & $\mathrm{c}$ \\
\hline $\mathrm{c}$ & $\mathrm{c}$ & $\mathrm{c}$ & $\mathrm{a}$ & 0 \\
\hline
\end{tabular}

Then $(\mathrm{X}, *, 0)$ is a PMS - algebra and $\mathrm{I}=\{0, \mathrm{a}, \mathrm{b}\}$ is a PMS-ideal.

In any PMS - algebra $\left(\mathrm{X},{ }^{*}, 0\right)$, with $\mathrm{x} \leq \mathrm{y}$, the following holds good for all $\mathrm{x}, \mathrm{y} \in \mathrm{X}$.

(i) $\mathrm{x} * \mathrm{x}=0$

(ii) $(\mathrm{y} * \mathrm{x}) * \mathrm{x}=\mathrm{y}$

(iii) $\mathrm{x} *(\mathrm{y} * \mathrm{x})=\mathrm{y} * 0$

(iv) $(\mathrm{y} * \mathrm{x}) * \mathrm{z}=(\mathrm{z} * \mathrm{x}) * \mathrm{y}$

(v) $0 * x=0 \Rightarrow x=0$

(vi) $(\mathrm{z} * \mathrm{x}) *(\mathrm{z} * \mathrm{y}) \leq \mathrm{x} * \mathrm{y}$

(vii) $\mathrm{x} \leq \mathrm{y} \Rightarrow \mathrm{z} * \mathrm{x} \leq \mathrm{z} * \mathrm{y}$ and $\mathrm{y} * \mathrm{z} \leq \mathrm{x} * \mathrm{z}$

(viii) $\mathrm{x} *((\mathrm{y} * \mathrm{x}) * \mathrm{x})=\mathrm{x} * \mathrm{y}$

(ix) $(\mathrm{x} * \mathrm{y}) * 0=\mathrm{y} * \mathrm{x}=(0 * \mathrm{y}) *(0 * \mathrm{x})$

(x) $0 *(\mathrm{x} * \mathrm{y})=(0 * \mathrm{x}) *(0 * \mathrm{y})$

(xi) $((\mathrm{y} * \mathrm{x}) * \mathrm{x}) * \mathrm{y}=0$

(xii) $(\mathrm{x} * \mathrm{y}) * \mathrm{x}=\mathrm{y}$.

Definition 2.6. [13] Let A be a non-empty subset of an algebra $X$, then $A$ is called a sub algebra of $\mathrm{X}$ if $\mathrm{x} * \mathrm{y} \in \mathrm{A}$, for all $\mathrm{x}, \mathrm{y} \in \mathrm{A}$. 
Definition 2.7. $[15,3]$ Let $X$ be a non-empty set. A fuzzy subset $\mu$ of the set $X$ is a mapping $\mu: X \rightarrow[0,1]$.

Definition 2.8. $[10,11]$ Let $\mu$ be a fuzzy set of $X$. For a fixed $t \in[0,1]$, the set $\mu_{t}=\{x \in$ $X / \mu(x) \geq t\}$ is called the upper level subset of $\mu$. Clearly $\mu^{t} \cup \mu_{t}=X$ for $t \in[0,1]$ if $\mathrm{t}_{1}<\mathrm{t}_{2}$, then $\mu_{\mathrm{t} 1} \subseteq \mu_{\mathrm{t} 2}$.

\section{Fuzzy PMS-ideal and fuzzy PMS-sub algebra}

Definition 3.1. Let $X$ be a PMS-algebra. A fuzzy set $\mu$ in $X$ is called a fuzzy PMS-ideal of $\mathrm{X}$ if it satisfies the following conditions.

i) $\mu(0) \geq \mu(x)$

ii) $\mu(\mathrm{y} * \mathrm{x}) \geq \min \{\mu(\mathrm{z} * \mathrm{y}), \mu(\mathrm{z} * \mathrm{x})\}$, for all $\mathrm{x}, \mathrm{y}, \mathrm{z} \in \mathrm{X}$

Definition 3.2. A fuzzy set $\mu$ in a PMS-algebra $X$ is called a fuzzy PMS- sub algebra of $\mathrm{X}$ if $\mu(\mathrm{x} * \mathrm{y}) \geq \min \{\mu(\mathrm{x}), \mu(\mathrm{y})\}$, for all $\mathrm{x}, \mathrm{y} \in \mathrm{X}$.

Definition 3.3. The set of elements that belong to the fuzzy set $\mu$ at least to the degree $t$ is called the $t$-level set. It is represented by $\mu^{t}=\{x \in X / \mu(x) \geq t\}$.

Theorem 3.4. Every fuzzy PMS-ideal of a PMS-algebra $X$ is order reversing.

Proof: Let $\mu$ be a fuzzy PMS-ideal of a PMS-algebra X.

Let $\mathrm{x}, \mathrm{y} \in \mathrm{X}$ be such that $\mathrm{x} \leq \mathrm{y}$, then $\mathrm{x} * \mathrm{y}=0$

Now $\mu(x) \geq \min \{\mu(0 * x)\}$

$$
\begin{aligned}
& =\min \{\mu(\mathrm{z} * 0), \mu((\mathrm{x} * \mathrm{y}) *(\mathrm{z} * \mathrm{y}))\} \\
& =\min \{\mu(\mathrm{z} * 0), \mu(0 *(\mathrm{z} * \mathrm{y}))\} \\
& =\min \{\mu(\mathrm{z} * 0), \mu(\mathrm{z} * \mathrm{y})\} \\
& =\min \{\mu(0 * 0), \mu(0 * \mathrm{y})\}(\text { Taking } \mathrm{z}=0) \\
& =\min \{\mu(0), \mu(\mathrm{y})\} \\
& =\mu(\mathrm{y}) \\
\Rightarrow \mu(\mathrm{x}) \geq \mu(\mathrm{y}) & \therefore \mu \text { is order reversing. }
\end{aligned}
$$

Theorem 3.5. Every fuzzy PMS-ideal of PMS-algebra is a fuzzy PMS-sub algebra.

Proof: Let $\mu$ be a fuzzy PMS-ideal.

To prove: $\mu$ is a fuzzy PMS- sub algebra of X.

By definition of fuzzy PMS - ideal, $\mu\left(y^{*} \mathrm{x}\right) \geq \min \left\{\mu(\mathrm{z} * \mathrm{y}), \mu\left(\mathrm{z}^{*} \mathrm{x}\right)\right\}$, for all $\mathrm{x}, \mathrm{y}, \mathrm{z} \in \mathrm{X}$ Now, $\mu(y * x) \geq \min \left\{\mu(\mathrm{z} * \mathrm{y}), \mu\left(\mathrm{z}^{*} \mathrm{x}\right)\right\}=\min \left\{\mu\left(0^{*} \mathrm{y}\right), \mu\left(0^{*} \mathrm{x}\right)\right\}=\min \{\mu(\mathrm{y}), \mu(\mathrm{x})\}$ $\Rightarrow \mu$ is a fuzzy PMS- subalgebra of $X$.

Theorem 3.6. The intersection of any set of fuzzy PMS - ideals in PMS-algebra is also a fuzzy PMS-ideal.

Proof: Let $\left\{\mu_{i}\right\}$ be a family of fuzzy PMS-ideals of PMS-algebras X. Then for any $x, y$, $\mathrm{z} \in \mathrm{X} .\left(\cap \mu_{\mathrm{i}}\right)(0)=\operatorname{Inf}\left(\mu_{\mathrm{i}}(0)\right)$

$$
\geq \operatorname{Inf}\left(\mu_{\mathrm{i}}(\mathrm{x})\right)
$$


P.M.Sithar Selvam and K.T.Nagalakshmi

$$
\begin{aligned}
& =\left(\cap \mu_{\mathrm{i}}\right)(\mathrm{x}) \\
\text { And }\left(\cap \mu_{\mathrm{i}}\right)\left(\mathrm{y}^{*} \mathrm{x}\right) & =\operatorname{Inf}\left(\mu_{\mathrm{i}}\left(\mathrm{y}^{*} \mathrm{x}\right)\right) \\
& \geq \operatorname{Inf}\left\{\min \left\{\mu_{\mathrm{i}}\left(\mathrm{z}^{*} \mathrm{y}\right), \mu_{\mathrm{i}}\left(\mathrm{z}^{*} \mathrm{x}\right)\right\}\right\} \\
& =\min \left\{\operatorname{Inf}\left(\mu_{\mathrm{i}}\left(\mathrm{z}^{*} \mathrm{y}\right)\right), \operatorname{Inf}\left(\mu_{\mathrm{i}}\left(\mathrm{z}^{*} \mathrm{x}\right)\right)\right\} \\
& =\min \left\{\left(\cap \mu_{\mathrm{i}}\right)\left(\mathrm{z}^{*} \mathrm{y}\right),\left(\cap \mu_{\mathrm{i}}\right)\left(\mathrm{z}^{*} \mathrm{x}\right)\right\}
\end{aligned}
$$

This completes the proof.

Theorem 3.7. A fuzzy set $\mu$ of a PMS - algebra is a fuzzy PMS - sub algebra if and only if the $t-$ level set, $\mu^{t}$ is either empty or a PMS - sub algebra of $X$, for every $t \in[0,1]$.

Proof : Assume that $\mu$ is a fuzzy PMS - sub algebra of $X$ and $\mu^{t} \neq \phi$

Then for any $\mathrm{x}, \mathrm{y} \in \mu^{\mathrm{t}}$, we have $\mu(\mathrm{x})=\mu(\mathrm{y})=\mathrm{t}$

$$
\begin{aligned}
\mu(\mathrm{x} * \mathrm{y}) & \geq \min \{\mu(\mathrm{x}), \mu(\mathrm{y})\} \\
& =\min \{\mathrm{t}, \mathrm{t}\}=\mathrm{t}
\end{aligned}
$$

There fore $\mathrm{x} * \mathrm{y} \in \mu^{\mathrm{t}}$.

Hence $\mu^{t}$ is a PMS - sub algebra of X.

Conversely, assume that $\mu^{\mathrm{t}}$ is a PMS - sub algebra of X.

Let $\mathrm{x}, \mathrm{y} \in \mathrm{X}$. Take $\mathrm{t}=\min \{\mu(\mathrm{x}), \mu(\mathrm{y})\}$

Then by assumption $\mu^{t}$ is a PMS - sub algebra of $X, x * y \in \mu^{t}$

$\mu(\mathrm{x} * \mathrm{y}) \geq \mathrm{t}=\min \{\mu(\mathrm{x}), \mu(\mathrm{y})\}$

Hence $\mu$ is a fuzzy PMS- sub algebra of $X$.

Theorem 3.8. Any sub algebra of a PMS - algebra X can be realized as a t-level sub algebra of some fuzzy PMS-sub algebra of X.

Proof: Let $\mu$ be sub algebra of the given PMS- algebra X.

Let $\mu$ be a fuzzy set in X defined by

$$
\mu(x)=\left\{\begin{array}{l}
t, \text { if } x \in A \\
0, \text { if } x \notin A
\end{array}\right.
$$

where $t \in[0,1]$ is fixed. It is clear that $\mu^{t}=A$.

Now we prove such defined $\mu$ is a fuzzy PMS- sub algebra of $X$.

Let $\mathrm{x}, \mathrm{y} \in \mathrm{X}$. If $\mathrm{x}, \mathrm{y} \in \mathrm{A}$, then $\mathrm{x} * \mathrm{y} \in \mathrm{A}$.

Hence, $\mu(x)=\mu(y)=\mu(x * y)=t$ and $\mu(x * y) \geq \min \{\mu(x), \mu(y)\}$

If $\mathrm{x}, \mathrm{y} \notin \mathrm{A}$, then $\mu(\mathrm{x})=\mu(\mathrm{y})=0$ and $\mu(\mathrm{x} * \mathrm{y}) \geq \min \{\mu(\mathrm{x}), \mu(\mathrm{y})\}=0$.

If at most one of $\mathrm{x}, \mathrm{y} \in \mathrm{A}$, then at least one of $\mu(\mathrm{x})$ and $\mu$ (y) is equal to 0 .

Therefore, $\min \{\mu(\mathrm{x}), \mu(\mathrm{y})\}=0$ so that $\mu(\mathrm{x} * \mathrm{y}) \geq 0$, which completes the proof.

As a generalisation of theorem 3.8, we prove the following theorem.

Theorem 3.9. Let $X$ be a PMS - algebra. Then given any chain of sub algebra $S_{0} \subset S_{1} \subset$ $\mathrm{S}_{2} \subset \ldots \subset \mathrm{S}_{\mathrm{r}}=\mathrm{X}$, there exists a fuzzy PMS-sub algebra $\mu$ of $\mathrm{X}$ whose t-level sub algebras are exactly the sub algebras of this chain.

Proof : Consider a set of numbers $t_{0}>t_{1}>t_{2}>\ldots \ldots \ldots>t_{r}$, where each $t_{i} \in[0,1]$.

Let $\mu: X \rightarrow[0,1]$ be a fuzzy set defined by $\mu\left(s_{0}\right)=t_{0}$ and $\mu\left(s_{i}-s_{i-1}\right)=t_{i}, 0<i \leq r$.

We claim that $\mu$ is a fuzzy PMS-sub algebra of $X$. Let $x, y \in X$. Then we classify it into two cases as follows :

Case (1) : Let $x, y \in s_{i}-s_{i-1}$. Then by the definition of $\mu, \mu(x)=t_{i}=\mu(y)$. 
Fuzzy PMS Ideals in PMS Algebras

Since $S_{\mathrm{i}}$ is a sub algebra, it follows that $\mathrm{x}^{*} \mathrm{y} \in \mathrm{S}_{\mathrm{i}}$, and so either $\mathrm{x} * \mathrm{y} \in \mathrm{S}_{\mathrm{i}}-\mathrm{S}_{\mathrm{i}-1}($ or $) \mathrm{x} * \mathrm{y} \in \mathrm{S}_{\mathrm{i}-1}$ In any case, we conclude that $\mu(\mathrm{x} * \mathrm{y}) \geq \mathrm{t}_{\mathrm{i}}=\min \{\mu(\mathrm{x}), \mu(\mathrm{y})\}$.

Case (2) : For $\mathrm{i}>\mathrm{j}$, Let $\mathrm{x} \in \mathrm{S}_{\mathrm{i}}-\mathrm{S}_{\mathrm{i}-1}$ and $\mathrm{y} \in \mathrm{S}_{\mathrm{j}}-\mathrm{S}_{\mathrm{j}-1}$.

Then $\mu(x)=t_{i} ; \mu(y)=t_{j}$ and $x * y \in S_{i}$, since $S_{i}$ is a subalgebra of $X$ and $S_{j} \subset S_{i}$.

Hence $\mu(\mathrm{x} * \mathrm{y}) \geq \mathrm{t}_{\mathrm{j}}=\min \{\mu(\mathrm{x}), \mu(\mathrm{y})\}$

Thus $\mu$ is a fuzzy PMS-subalgebra of $X$.

From the definition of $\mu$,it follows that $\operatorname{Im}(\mu)=\left\{t_{0}, t_{1}, t_{2}, \ldots \ldots \ldots t_{r}\right\}$.

Hence the t-level subalgebras of $\mu$ are given by the chain of subalgebras.

$\mu_{\mathrm{t} 0} \subset \mu_{\mathrm{t} 1} \subset \mu_{\mathrm{t} 2} \subset \ldots \ldots \ldots \ldots \ldots \mu_{\mathrm{tr}}=\mathrm{X}$.

Now $\mu_{\mathrm{t} 0}=\left\{\mathrm{x} \in \mathrm{X} / \mu(\mathrm{x}) \geq \mathrm{t}_{0}\right\}=\mathrm{S}_{0}$.

Finally, we prove that $\mu_{\mathrm{ti}}=\mathrm{S}_{\mathrm{i}}$ for $0<\mathrm{i} \leq \mathrm{r}$.

Clearly $S_{\mathrm{i}} \subseteq \mu_{\mathrm{ti}}$.

If $x \in \mu_{t i}$, then $\mu(x) \geq t_{i}$ which implies that $x \notin S_{j}$ for $j>i$.

Hence $\mu(\mathrm{x}) \in\left\{\mathrm{t}_{1}, \mathrm{t}_{2}, \ldots \ldots \ldots \mathrm{t}_{\mathrm{i}}\right\}$ and so $\mathrm{x} \in \mathrm{S}_{\mathrm{k}}$ for some $\mathrm{k} \leq \mathrm{i}$.

As $S_{\mathrm{k}} \subseteq \mathrm{S}_{\mathrm{i}}$, it follows that $\mathrm{x} \in \mathrm{S}_{\mathrm{i}} . \Rightarrow \mu_{\mathrm{ti}}=\mathrm{S}_{\mathrm{i}}$ for $0<\mathrm{i} \leq \mathrm{r}$.

This completes the proof.

Theorem 3.10. Two level sub algebras $\mu^{\mathrm{s}}, \mu^{\mathrm{t}}(\mathrm{s}<\mathrm{t})$ of a fuzzy PMS- algebras are equal if and only if there is no $\mathrm{x} \in \mathrm{X}$ such that $\mathrm{s} \leq \mu(\mathrm{x})<\mathrm{t}$.

Proof: Let $\mu^{\mathrm{s}}=\mu^{\mathrm{t}}$ for some $\mathrm{s}<\mathrm{t}$.

If there exist $\mathrm{x} \in \mathrm{X}$ such that $\mathrm{s} \leq \mu(\mathrm{x})<\mathrm{t}$, then $\mu^{\mathrm{t}}$ is a proper subset of $\mu^{\mathrm{s}}$, which is a contradiction.

Conversely, assume that there is no $\mathrm{x} \in \mathrm{X}$ such that $\mathrm{s} \leq \mu(\mathrm{x})<\mathrm{t}$, since $\mathrm{s}<\mathrm{t}, \mu^{\mathrm{t}} \subseteq \mu^{\mathrm{s}}$.

If $x \in \mu^{s}$ then $\mu(x) \geq s$ and so $\mu(x) \geq t$, because $\mu$ (x) does not lie between $s$ and $t$.

Hence $\mathrm{x} \in \mu^{\mathrm{t}}$, which gives $\mu^{\mathrm{s}} \subseteq \mu^{\mathrm{t}}$. This completes the proof.

Theorem 3.11. Let $\mu$ be a fuzzy set in a PMS-algebra $X$ and let $t \in \operatorname{Im}(\mu)$. Then $\mu$ is a fuzzy PMS-ideal of $X$ if and only if the t-level subset $\mu^{t}$ is a PMS-ideal of X.

Proof : Assume that $\mu$ is a fuzzy PMS-ideal of X.

Clearly $0 \in \mu^{\mathrm{t}}$.

Let $z^{*} \mathrm{x} \in \mu^{\mathrm{t}}$ and $\mathrm{z} * \mathrm{y} \in \mu^{\mathrm{t}}$.

Then $\mu(\mathrm{z} * \mathrm{x}) \geq \mathrm{t}$ and $\mu(\mathrm{z} * \mathrm{y}) \geq \mathrm{t}$

Now $\mu(y * x) \geq \min \{\mu(\mathrm{z} * \mathrm{y}), \mu(\mathrm{z} * \mathrm{x})\} \geq \min \{\mathrm{t}, \mathrm{t}\}=\mathrm{t}$.

Hence the t-level subset $\mu^{t}$ is a PMS-ideal of $X$.

Conversely assume that, the t-level subset $\mu^{t}$ is a PMS-ideal of $X$, for any $t \in[0,1]$.

Suppose assume that there exist some $\mathrm{x}_{0} \in \mathrm{X}$ such that $\mu(0)<\mu\left(\mathrm{x}_{0}\right)$

Take $s=\frac{1}{2}\left[\mu(0)+\mu\left(x_{0}\right)\right]$

$\Rightarrow \mu(0)<\mathrm{s}<\mu\left(\mathrm{x}_{0}\right)$

$\Rightarrow \mathrm{x}_{0} \in \mu^{\mathrm{s}}$ and $0 \notin \mu^{\mathrm{s}}$, a contradiction, since $\mu^{\mathrm{s}}$ is a PMS-ideal of $\mathrm{X}$.

Therefore, $\mu(0) \geq \mu(\mathrm{x})$ for all $\mathrm{x} \in \mathrm{X}$.

If possible, assume that $\mathrm{x}_{0}, \mathrm{y}_{0}, \mathrm{z}_{0} \in \mathrm{X}$ such that $\mu\left(\mathrm{y}_{0} * \mathrm{x}_{0}\right)<\min \left\{\mu\left(\mathrm{z}_{0} * \mathrm{y}_{0}\right), \mu\left(\mathrm{z}_{0} * \mathrm{x}_{0}\right)\right\}$.

Take $\mathrm{s}=\frac{1}{2}\left[\mu\left(\mathrm{y}_{0} * \mathrm{x}_{0}\right)+\min \left\{\mu\left(\mathrm{z}_{0} * \mathrm{y}_{0}\right), \mu\left(\mathrm{z}_{0} * \mathrm{x}_{0}\right)\right\}\right]$

$\Rightarrow \mathrm{s}>\mu\left(\mathrm{y}_{0} * \mathrm{x}_{0}\right)$ and $\mathrm{s}<\min \left\{\mu\left(\mathrm{z}_{0} * \mathrm{y}_{0}\right), \mu\left(\mathrm{z}_{0} * \mathrm{x}_{0}\right)\right\}$.

$\Rightarrow \mathrm{s}>\mu\left(\mathrm{y}_{0} * \mathrm{x}_{0}\right), \mathrm{s}<\mu\left(\mathrm{z}_{0} * \mathrm{y}_{0}\right)$ and $\mathrm{s}<\mu\left(\mathrm{z}_{0} * \mathrm{x}_{0}\right)$. 
P.M.Sithar Selvam and K.T.Nagalakshmi

$\Rightarrow \mathrm{y}_{0} * \mathrm{x}_{0} \notin \mu^{\mathrm{s}}$, a contradiction, since $\mu^{\mathrm{s}}$ is a PMS-ideal of $\mathrm{X}$.

Therefore $\mu(y * x) \geq \min \{\mu(\mathrm{z} * \mathrm{y}), \mu(\mathrm{z} * \mathrm{x})\}$, for any $\mathrm{x}, \mathrm{y}, \mathrm{z} \in \mathrm{X}$.

Theorem 3.12. Let $X$ be a PMS-algebra $\& \mu$ be a fuzzy PMS-sub algebra of $X$. If $\operatorname{Im}(\mu)$ is finite, say $\left\{\mathrm{t}_{1}, \mathrm{t}_{2}, \ldots \mathrm{t}_{\mathrm{r}}\right\}$, then for any $\mathrm{t}_{\mathrm{i}}, \mathrm{t}_{\mathrm{j}} \in \operatorname{Im}(\mu), \mu_{t_{\mathrm{i}}}=\mu_{t_{j}}$, implies $\mathrm{t}_{\mathrm{i}}=\mathrm{t}_{\mathrm{j}}$.

Proof : Assume that $t_{i} \neq t_{j}$ say $t_{i}<t_{j}$.

If $\mathrm{x} \in \mu_{z_{j}}$ then $\mu(\mathrm{x}) \geq \mathrm{t}_{\mathrm{j}}>\mathrm{t}_{\mathrm{i}}$, which implies that $\mathrm{x} \in \mu_{\mathrm{t}_{\mathrm{i}}}$.

Let $\mathrm{x} \in \mathrm{X}$ be such that $\mathrm{t}_{\mathrm{i}}<\mu(\mathrm{x})<\mathrm{t}_{\mathrm{j}}$. Then $\mathrm{x} \in \mu_{\mathrm{t}_{i}}$, but $\mathrm{x} \notin \mu_{\mathrm{t}_{j}}$.

Hence $\mu_{t_{i}} \not \subset \mu_{t_{j}}$ and $\mu_{t_{j}}=\mu_{t_{i}}$, a contradiction.

\section{Conclusion}

In this article, we have been discussed some charecterizations of fuzzy PMS-algebras. It adds an another dimension to the defined PMS--algebras. This concept can further be generalized to soft sets, rough sets and in bi-polar fuzzy for new results in our future work.

\section{Acknowledgement}

Authors wish to thank Dr.T.Priya, Faculty of Mathematics, Omen and to anonymous referees, Editor-in-chief, for their comments, suggestions and ideas to improve and make this paper as successful one.

\section{REFERENCES}

1. K.Iseki and S.Tanaka, An introduction to the theory of BCK-algebras, Math Japonica, 23 (1978) 1-20.

2. K.Iseki, On BCI-algebras, Math. Seminar Notes, 8 (1980) 125-130.

3. K.Megalai and A.Tamilarasi, Fuzzy subalgebras and fuzzy T-ideals in TM-algebra, Journal of Mathematics and Statistics, 7(2) (2011) 107-111.

4. P.M.Sithar Selvam and K.T.Nagalakshmi, On PMS-algebras, Transylvanian Review, 24(10) (2016) 1622-1628.

5. P.M.Sithar Selvam and K.T.Nagalakshmi, Homomorphism and Cartesian product on fuzzy $\alpha$-translation and fuzzy $\alpha$-multiplication of PMS-algebras, Transylvanian Review, 24(10) (2016) 1630-1638.

6. P.M.Sithar Selvam and K.T.Nagalakshmi, Anti Q-fuzzy PMS-ideals in PMSalgebras, International Journal of Mathematics Trends and Technology, 38(4) (2016)

7. P.M.Sithar Selvam, T.Priya and T.Ramachandran, Anti fuzzy subalgebras and homomorphism of CI-algebras, International Journal of Engineering Research \& Technology, 1(5) (2012) 1-6.

8. P.M.Sithar Selvam and K.T.Nagalakshmi, A study on normalization of fuzzy PMSalgebras, International Journal of Trend in Research and Development, 3(6) (2016) 49-55.

9. P.M.Sithar Selvam and K.T.Nagalakshmi, Role of homomorphism and Cartesian product over fuzzy PMS-algebras, International Journal of Fuzzy Mathematical Archive, 11(1) (2016) 31-38. 
Fuzzy PMS Ideals in PMS Algebras

10. T.Priya and T.Ramachandran, A note on fuzzy PS-ideals in PS-algebra and its level subsets, International Journal of Advanced Mathematical Sciences, 2(2) (2014) 101-106.

11. T.Priya and T.Ramachandran, Some Characterization of Anti fuzzy PS-ideals of PSalgebras in Homomorphism and Cartesian Products, International Journal of Fuzzy Mathematical Archive, 4(2) (2014) 72-79.

12. T.Priya and T.Ramachandran, A note on anti Q-Fuzzy R-closed PS-ideals in PSalgebras, Annals of Pure and Applied Mathematics, 6(2) (2014) 150-159.

13. T.Priya and T.Ramachandran, Homomorphism and Cartesian product on fuzzy translation and fuzzy multiplication of PS-algebras, Annals of Pure and Applied Mathematics, 8(1) (2014) 93-104.

14. T.Senapati, M.Bhowmik and M.Pal, Atanassov's intuitionistic fuzzy translations of intuitionistic fuzzy $\mathrm{H}$-ideals in $B C K / B C I$-algebras, Notes on Intuitionistic Fuzzy Sets, 19 (2013) 32-47.

15. L.A.Zadeh, Fuzzy sets, Information and Control, 8 (1965) 338-353. 